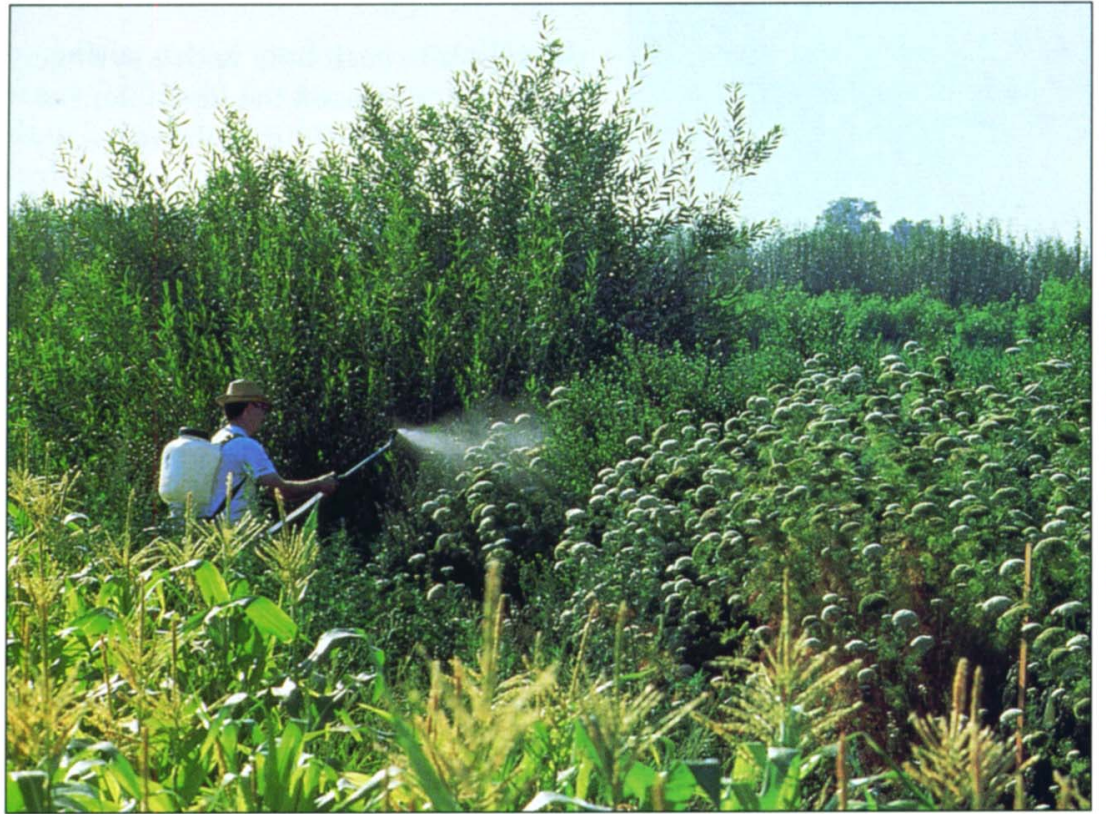

\section{Beneficial insects move from flowering plants to nearby crops}

\author{
Rachael Freeman Long $\sqcup$ Andrew Corbett $\sqcup$ Celia Lamb \\ Chris Reberg-Horton $\square$ Jeff Chandler $\square$ Michael Stimmann
}

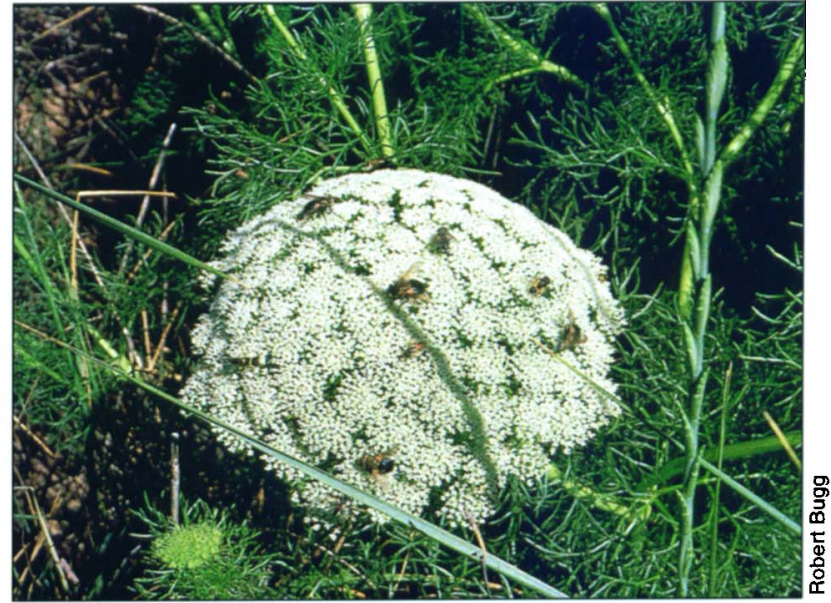

$\Delta$ A close up of toothpick weed (A. visnaga) covered with beneficial insects.

4 Entomologist Andrew Corbett sprays a rubidium solution onto toothpick weed (A. visnaga) at Lindell Farms in Fresno County to track the movement of beneficial insects.

\section{Marking studies demonstrated that lady beetles, lacewings, syr- phid flies and parasitic wasps fed on nectar or pollen provided by borders of flowering plants around farms; many insects moved 250} feet into adjacent field crops. Studies using the elemental marker rubidium also showed that syrphid flies, parasitic wasps and lacewings fed on flowering cover crops in orchards and that some moved 6 feet high in the tree canopy and 100 feet away from the treated area. The use of nectar or pollen by beneficial insects helps them survive and reproduce. Therefore, planting flowering plants and perennial grasses around farms may lead to better biological control of pests in nearby crops.
California farmers are planting strips or borders of flowering plants and perennial grasses, termed insectary plantings, around their farms to attract beneficial insects and thus get better biological control of pests in their crops. The idea behind these plantings is that many adult beneficial insects feed on nectar or pollen as a sole food source or to supplement their diet during periods of prey scarcity. These critical nutrients help them survive and increase their egg-laying ability. To the extent that these food resources lead to more beneficial insects around farms, insectary plantings may result in greater biological pest control.

While these plantings seem like a good idea, there are few data to support their application as an effective biocontrol tool. The objective of this study was to determine if beneficial insects feed on insectary plants and then move into associated crops.

\section{Insectary plants}

Insectary plants are those that produce nectar or pollen and attract beneficial insects. These include perennial and annual plants (tables 1 and 2) and perennial grasses such as deergrass (Muhlenbergia rigens), purple needlegrass (Nassella pulchra), blue wild rye (Elymus glaucus), meadow barley (Hordeum brachyantherum), California brome (Bromus carinatus) and Yolo slender wheatgrass (Elymus trachycaulus majus). Insectary plantings that contain a variety of plants with different flowering periods provide a yearround food supply for beneficial insects.

\section{Using rubidium to track insects}

Rubidium ( $\mathrm{Rb}$ ) was used to document the feeding by beneficial insects at insectary plantings and their movement into adjacent crops. This element substitutes for the potassium in plant and insect tissues. Tests have shown that at low concentrations rubidium does not have any detectable effects on longevity or behavior of most insects (Stimmann et al. 1973). It can also be easily tracked in biological systems through the use of a flame emission spectrophotometer.

Beneficial insects were labeled by injecting or spraying solutions of rubidium chloride $(\mathrm{RbCl})$ into or on in- 


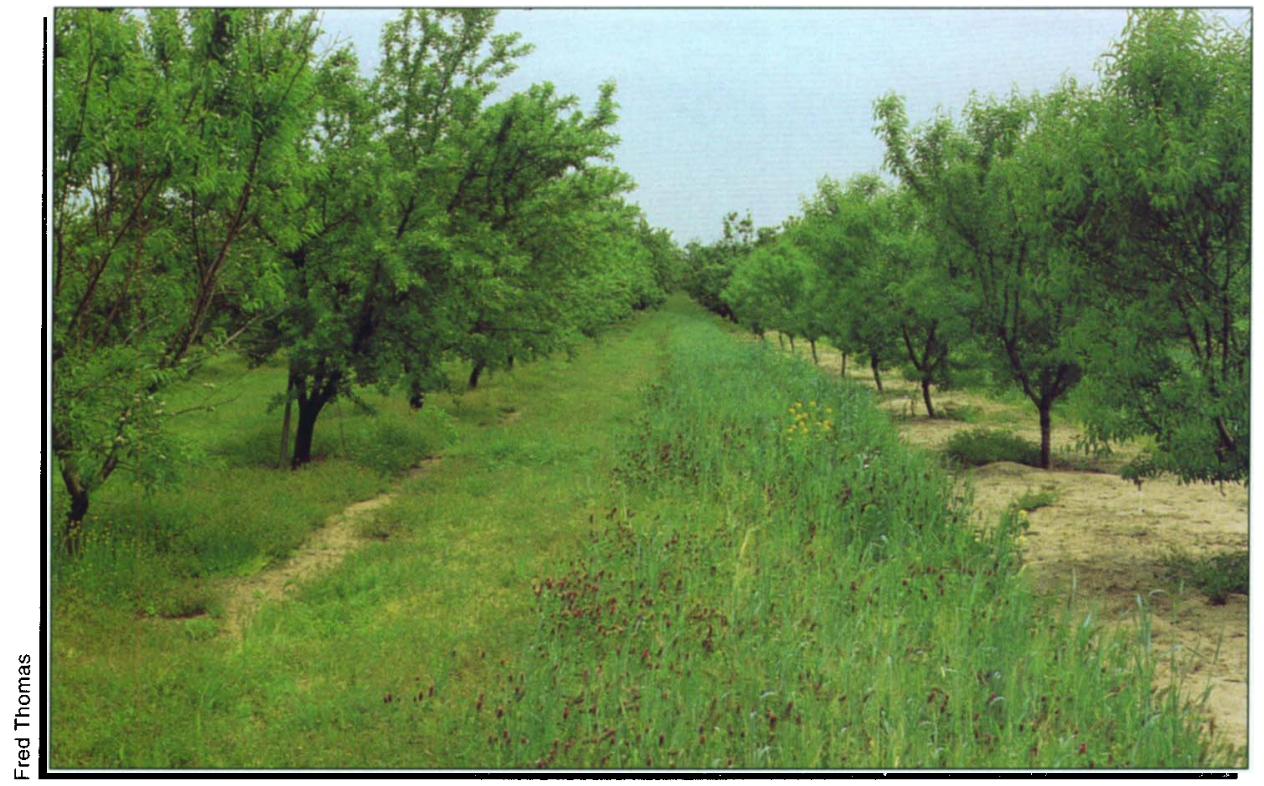

At the almond orchard site, lacewings, syrphid flies and parasitic wasps moved up to 100 feet away from the insectary plantings. sectary plants. The insects obtained the label through feeding on Rb-rich nectar and pollen sources that concentrated in the plant. Because $\mathrm{Rb}$ occurs naturally in plant and insect tissues at fairly low and uniform levels, relatively small increases in $\mathrm{Rb}$ result in a measurable label at levels above the natural background concentration normally found in insects (Berry et al. 1972).

\section{Three field sites}

From 1994 to 1995, we conducted studies at three field sites where insectary plantings are being used by growers. The first site was at Hedgerow Farms in Yolo County, with fourteen 10-year-old California lilac (Ceanothus 'Ray Hartman') bushes located directly across from a wheat field. The second site was at Lindell Farms in
Fresno County, with a 2-year-old, 20foot-wide-by-660-foot-long hedgerow of perennials (table 1 ) and annual toothpick weed (Ammi visnaga). This insectary planting was surrounded by organic vegetables including beans, corn and tomatoes, and a small orchard of peaches and walnuts. The third site was in an almond orchard in Merced County, where a grower planted a mix of winter insectary annuals in 1 out of every 10 tree rows (table 2 ).

\section{Rubidium applied to plants}

We injected $\mathrm{RbCl}$ into the California lilac plants at Hedgerow Farms. This was done once before bloom, by drilling one or two holes into each main branch at the base of the plant and injecting 7 milliliters of $\mathrm{RbCl}$ solution (at a very high concentration of $0.25 \mathrm{gm}$ per $\mathrm{mL}$ ) into each hole with a syringe. Injections increased the $\mathrm{Rb}$ content of plants by about 10 times the naturally occurring background levels. The Lindell Farms site was sprayed with $\mathrm{RbCl}$ at 3,000 ppm about every 2 weeks from June until August. At the almond orchard site, four cover crop strips ( $6 \mathrm{ft}$ by $1,000 \mathrm{ft}$ ) were sprayed with $\mathrm{RbCl}$ at 3,000 ppm about every 2 weeks from May to July. $\mathrm{RbCl}$ sprays increase the $\mathrm{Rb}$ content by 200 times the naturally occurring background levels.

\section{Sampling beneficial insects}

Following $\mathrm{RbCl}$ applications, we collected beneficial insects from the insectary plants and the associated crop using 6-inch-by-12-inch sticky cards of similar color to standard yellow whitefly traps. Only those beneficial insects believed important to pest management in the crops were collected for $\mathrm{Rb}$ analysis (table 3 ).

At Hedgerow Farms, we suspended 8 traps in the canopy of individual California lilac shrubs. In the adjacent wheat, we stapled 20 traps onto wooden stakes at the level of the crop at distances of 50 feet, 150 feet, 250 feet and 450 feet from the California lilac. We changed all of the traps every 2 weeks from April until May.

At Lindell Farms, we placed 10 traps on wooden stakes every 50 feet, adjacent to and just below the height of the insectary plants. In the adjacent vegetable crops, 20 traps were stapled onto wooden stakes below the level of the crop at distances of 20 feet and 250 feet from the insectary plants. In the adjacent orchard, 20 traps were placed 6 feet high in individual trees at 50 foot intervals, from 20 feet to 250 feet away from the hedgerow. Traps were changed every 2 weeks from June to August. We collected Hyposoter wasps using a handheld aspirator, as we did not find them on sticky traps.

At the almond orchard site, we placed 36 traps 6 feet high in individual trees ( $24 \mathrm{ft}$ by $24 \mathrm{ft}$ spacing) at 1,3 and 5 tree rows from the insectary mix strips. Traps were changed every 2 weeks from May until July.

We removed the beneficial insects from the traps, then identified and analyzed them for $\mathrm{Rb}$ content. Similar 
beneficial insect species were collected from "control" fields, located more than 2 miles away from treated hedgerows, to determine the naturally occurring background $\mathrm{Rb}$ content. Trichogramma controls were obtained from a laboratory colony. These data provided the criteria for deciding if an individual beneficial insect captured within the insectary plantings and associated crops was labeled (table 4).

\section{Analysis of samples}

Insects were chemically digested and analyzed for $\mathrm{Rb}$ content using standard methodologies (Berry et al. 1972). Insects were considered labeled if their $\mathrm{Rb}$ concentration was more than three standard deviations greater than the control means. In this way, the probability of incorrectly identifying an insect as labeled with $\mathrm{Rb}$ is very low (less than $1 \%$ ).

\section{Labeling of beneficial insects}

Hedgerow Farms. In the California lilac, $67 \%$ (sample size of $n=15$ ) of the green lacewings, and $40 \%(n=10)$ of the lady beetles were labeled with $\mathrm{Rb}$, following injections with $\mathrm{RbCl}$. In the adjacent wheat, $2 \%$ of the green lacewings were labeled at 50 feet and $2 \%$ were labeled at 450 feet $(n=47)$. We did not find any labeled lady beetles in the adjacent wheat.

Lindell Farms. $\mathrm{RbCl}$ sprays in the insectary hedgerow also resulted in marking of beneficial insects (fig. 1). In the insectary plantings, $61 \%$ of the green lacewings were labeled, plus $20 \%$ of the Trichogramma, and $55 \%$ of the lady beetles. We did not find any labeled Hyposoter wasps in the insec- tary plantings, even though these wasps are known to feed on nectar of flowering plants. We suspect that these wasps were visiting the plants in a manner that escaped our detection, possibly due to the time of day or their foraging behavior.

In the adjacent vegetables (fig. 1), $24 \%$ of the green lacewings were labeled 20 feet from the hedgerow, but none were labeled at 250 feet. For lady beetles, $27 \%$ were labeled at 20 feet and $23 \%$ were labeled at 250 feet from the hedgerow. For Hyposoter wasps, $17 \%$ were labeled at 20 feet and $47 \%$ were labeled at 250 feet from the hedgerow. None of the Trichogramma were labeled in the nearby crops.

In the adjacent orchard, $10 \%$ of the green lacewings were labeled at 20 feet $(n=31)$ and $33 \%(n=3)$ were labeled beled green lacewings were found in the trees at any other distances $(n<3$ for all these samples). Ten percent of the lady beetles $(n=10)$ and $2.5 \%(n=$ 40) of the Trichogramma were labeled at 20 feet from the hedgerow.

Almond orchard site. $\mathrm{RbCl}$ marking of the annual insectary mix also showed labeling of beneficial insects (fig. 2). In the trees, $27 \%$ of the green at 150 feet from the hedgerow. No la-

lacewings were labeled adjacent to the insectary mix, but none were labeled further away. For brown lacewings, $39 \%$ were labeled next to the insectary mix, $28 \%$ were labeled at 50 feet and $17 \%$ were labeled at 100 feet. For syrphid flies, $81 \%$ were labeled adjacent to the insectary $\mathrm{mix}, 74 \%$ were labeled at 50 feet, and $70 \%$ were labeled at 100 feet. For Macrocentrus wasps, $8.1 \%$ were labeled next to the insectary mix, $4.3 \%$ were labeled at 50 feet, and $4.5 \%$ were labeled at 100 feet.

\section{Underestimation of numbers}

Although the percentage of labeled beneficial insects was low in some samples, these data probably underestimate the numbers of beneficial in-

$\begin{gathered}\text { TABLE 2. Winter annual insectary plants at the } \\
\text { almond orchard }\end{gathered}$
\begin{tabular}{ll} 
Common Name & \multicolumn{1}{c}{ Taxon } \\
\hline Subterranean clover & Trifolium subterraneum \\
Common vetch & Vicia sativa \\
White sweetclover & Trifolium repens \\
Crimson clover & Trifolium incarnatum \\
Rye & Secale cereale \\
Triticale & X Triticosecale \\
Barley & Hordeum vulgare \\
Bee phacelia & Phacelia tanacetifolia \\
Coriander & Coriandrum sativum \\
Sweet alyssum & Lobularia maritima \\
Tidy tips & Layia platyglossa \\
Celery & Apium graveolens \\
\hline
\end{tabular}

TABLE 3. Dominant beneficial insects collected and analyzed for rubidium content at our study sites

\begin{tabular}{lll}
\hline \hline Beneficial insect & Taxon & Primary prey \\
\hline Green lacewings & Chrysoperla carnea & Aphids \\
Brown lacewings & Hemerobius sp. & Aphids \\
Lady beetles & Hippodamia convergens & Aphids \\
Syrphid flies & Toxomerus sp. & Aphids \\
Parasitic wasps & Hyposoter sp. & Caterpillars \\
& Trichogramma sp. & Moth eggs \\
& Macrocentrus sp. & Peach twig borers \\
& & Leafrollers \\
\hline
\end{tabular}

TABLE 4. Highest rubidium level found in beneficial insects in crops versus naturally occurring background levels (controls)

\begin{tabular}{|c|c|c|c|c|c|c|c|}
\hline \multirow[b]{2}{*}{ Beneficial insects } & \multicolumn{3}{|c|}{ Crops } & \multicolumn{3}{|c|}{ Control } & \multirow{2}{*}{$\begin{array}{l}\text { Source of } \\
\text { controls }\end{array}$} \\
\hline & \multicolumn{3}{|c|}{3 highest $\mathbf{R b}$ values* } & Mean & deviation & Sample size & \\
\hline & \multicolumn{6}{|c|}{ nanograms of $R b$ per insect } & \\
\hline Green lacewings & 2,000 & 1,200 & 1,000 & 89 & 58 & 94 & Wheat \\
\hline Brown lacewings & 486 & 369 & 255 & 18 & 13 & $18 \dagger$ & Wheat \\
\hline Lady beetles & 1,000 & 940 & 900 & 64 & 36 & 220 & Wheat \\
\hline Hyposoter wasps & 330 & 300 & 280 & 15 & 14 & 34 & Sugarbeet \\
\hline Syrphid flies & 1,240 & 1,240 & 600 & 14 & 5 & $24 \ddagger$ & Almonds \\
\hline Macrocentrus wasps & 43 & 28 & 28 & 3 & 1 & 67 & Almonds \\
\hline Trichogramma wasps & 1.6 & 1.4 & 0.7 & 0.1 & 0.15 & $26 \S$ & Lab-reared colony \\
\hline
\end{tabular}

"Insects were considered labeled if their Rb concentration was more than 3 standard deviations from the control means. For normally distributed populations this means that $P<0.001$. For sample sizes less than 30 , the following standard deviations were used: $\nmid 4.0, \ddagger 3.8$ and $\S 3.7$. 


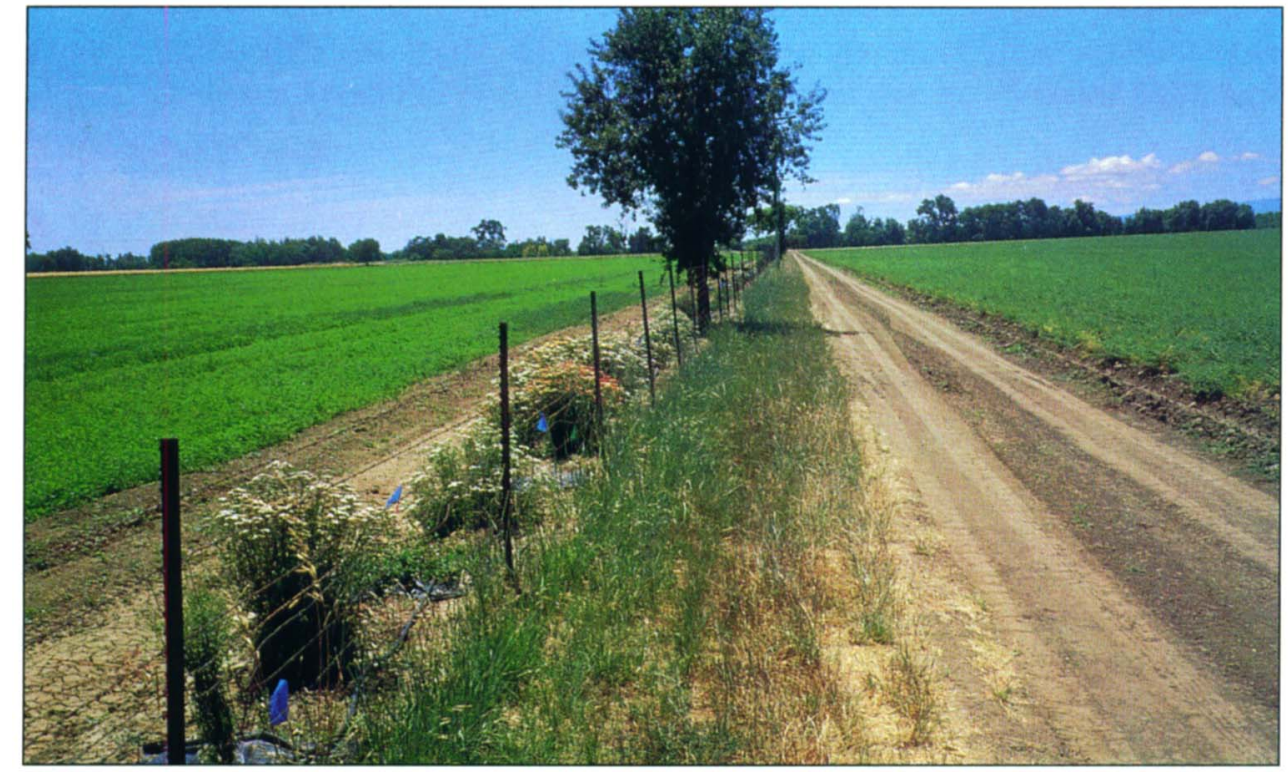

Hedgerow of insectary shrubs and native grasses, Yolo County.

sects that are using the insectary plants. Our laboratory studies showed that green lacewings need to feed on $\mathrm{Rb}$-marked floral resources for up to 24 hours to acquire detectable levels of $\mathrm{Rb}$. If beneficial insects are feeding on both marked and unmarked plants in the field, the impact of the Rb label will likely be diluted. For example, at Hedgerow Farms, where we had low levels of labeling, there is an abundance of floral resources other than

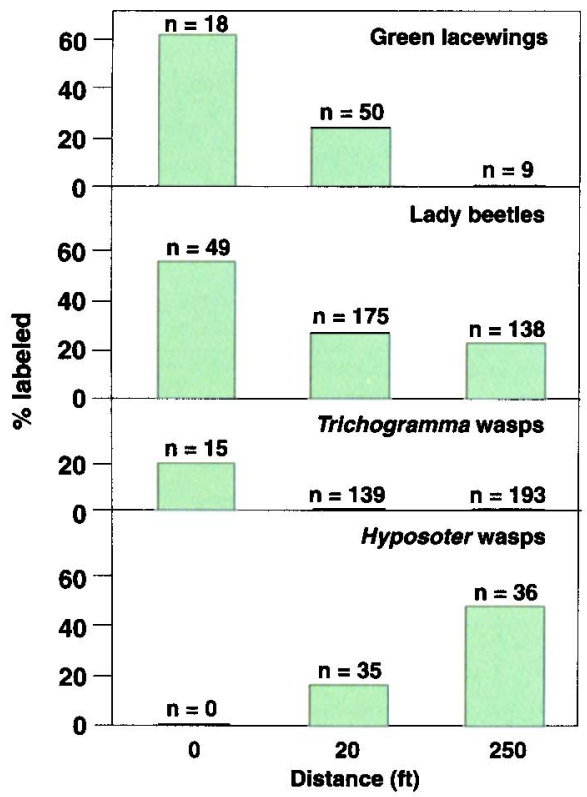

Fig. 1. Percent Rb-labeled beneficial insects in the insectary hedgerow $(0 \mathrm{ft})$ and in the adjacent vegetable crop at $20 \mathrm{ft}$ and $250 \mathrm{ft}$ ( $\mathrm{n}=$ total number of insects captured). our Rb-marked California lilac for beneficial insects to feed on. In addition, our laboratory studies showed that green lacewings excrete the label within 24 hours.

The results of this study demonstrate that beneficial insects feed on nectar or pollen provided by insectary plants, and that they move into associated crops. Because many Rb-labeled individuals were trapped 250 feet from the insectary plants, our data

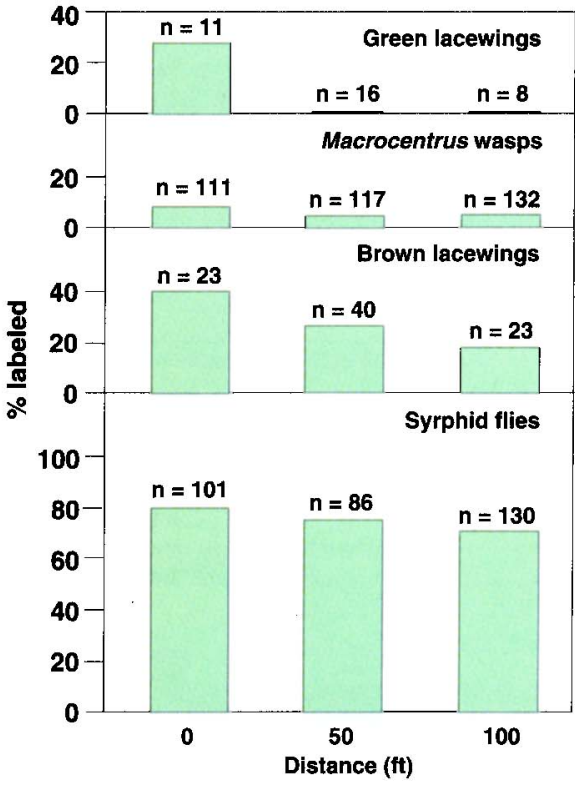

Fig. 2. Percent Rb-labeled beneficial insects trapped in the almond trees at 0,50 and $100 \mathrm{ft}$ from the Rb-labeled insectary cover crop mix ( $n=$ total number of insects captured).

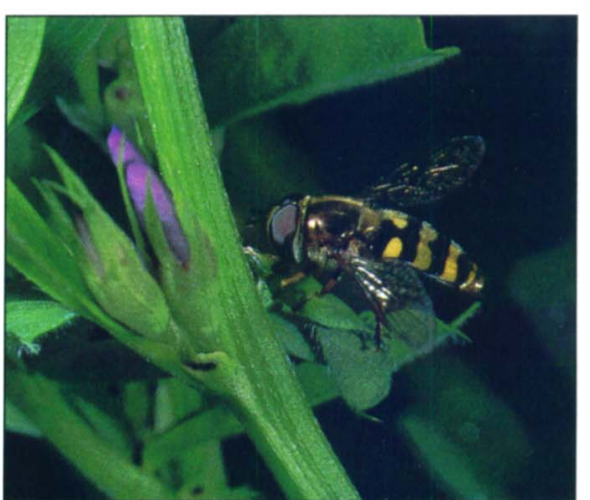

Scientists found that $70 \%$ of the syrphid flies in almond trees were marked with rubidium 100 feet away from the insectary planting. suggest strips or borders of flowering plants may help beneficial insects even at long distances. The survival of many beneficial insect species depends on nectar or pollen so adding insectary plantings to the agricultural landscape may enlarge their populations and increase their activity in crops.

R. Freeman Long is UC Cooperative Extension Farm Advisor, Yolo and Solano counties; A. Corbett is Postdoctoral Researcher, Entomology, UC Davis; C. Lamb is Field Assistant, Agronomy, UC Davis; C. Reberg-Horton is Graduate Student, Agronomy, UC Davis; J. Chandler is Consultant, Corn Flower Farms, Elk Grove; and M. Stimmann is Extension Environmental Toxicologist, UC Davis.

This research was supported by the California Tomato Research Institute and the U.S. Environmental Protection Agency.

\section{References}

Berry WL, Stimmann MW, Wolf WW. 1972. Marking of phytophagous native insects with rubidium: A proposed technique Annals Ento 65:236-8.

Stimmann MW, Wolf WW, Berry WL. 1973. Cabbage loopers: The biological effects of rubidium in the larval diet. $J$ Econ Entomol 66:324-6.

Bugg RL, Anderson JH, Thomsen CD, Chandler J. 1998. Farmscaping: Restoring native biodiversity to agricultural settings. In Pickett $\mathrm{CH}$ and Bugg RL (Eds.) Enhancing biological control: habitat management to promote natural enemies of agricultural pests. University of California Press, Berkeley, CA. (In press). 